\title{
Penerapan Pembelajaran Kompetitif Guna Mengembangkan Karakter Siswa Dalam Pembelajaran Bola Voli
}

Iyam Siti Maryamah ${ }^{1}$, Suherman Selamat ${ }^{1}$, Yeyet Hapsyah $^{2}$

${ }^{1}$ Program Studi Pendidikan Guru Sekolah Dasar Pendidikan Jasmani, Universitas Pendidikan Indonesia

${ }^{2}$ SD Negeri 3 Sukaluyu Bandung

\begin{tabular}{|c|}
\hline Info Artikel \\
\hline SejarahArtikel: \\
\hline Diterima Januari \\
\hline Disetujui Maret 2018 \\
\hline Dipublikasikan Mei 2018 \\
\hline
\end{tabular}

Keywords:

Karakter Siswa, Pembelajaran Bola Voli, Pembelajaran Kompetitif

\begin{abstract}
Abstrak
Penelitian ini bertujuan untuk mengembangkan karakter siswa kelas IV SDN 3 Sukaluyu Bandung melalui penerapan pembelajaran kompetitif dalam pembelajaran bola voli. Penelitian ini menggunakan metode penelitian tindakan kelas (Classroom Action Research). Subjek penelitian merupakan siswa kelas IV yang berjumlah 35 Siswa dari 24 siswa laki-laki dan 10 siswa perempuan. Penelitian ini menggunakan model Kemmis dan Mc Taggart, penelitian ini dilaksanakan dalam dua siklus. Dengan menggunakan desain penelitian atau langkah-langkah penelitian tindakan yaitu, Perencanaan (planning), Tindakan (Action), Pengamatan (Observing), dan Refleksi (Reflecting). Aspek karakter pada penelitian ini meliputi tanggung jawab, sportivitas, dan kerjasama dinilai dengan menggunakan teknik observasi. hasil penelitian di dapat hasil proses pembelajaran siswa Pra siklus $28,82 \%$, pada siklus I tindakan I $(37,63 \%)$, siklus I tindakan II (43,92\%), siklus II tindakan I (53,06\%), dan siklus II tindakan II $(63,43 \%)$. Dapat disimpulkan bahwa penerapan pembelajaran kompetitif dapat mengembangkan karakter siswa kelas IV SDN 3 sukaluyu Bandung dalam pembelajaran bola voli.
\end{abstract}

\begin{abstract}
This study aims to develop the character of fourth grade students of SDN 3 Sukaluyu Bandung by using the application of competitive learning in volleyball learning. The methods used is classroom action research (Classroom Action Research). The subjects of the fourth grade study were 35 students from 24 male students and 10 female students. This research uses Kemmis and Mc Taggart model, this research is conducted in two cycles. By using research design or action research steps that is, planning (planning), Action (Action), Observation (Observing), and Reflection (Reflecting). Instruments in this study using student character observation sheets, field notes, documentation, and evaluation. Based on the results of the research in the results of the learning process of students Pre cycle $28.82 \%$, in the first cycle action I (37.63\%), cycle I action II (43.92\%), cycle II action I (53.06\%), and second cycle II action $(63,43 \%)$. From the results of data processing and data analysis can be concluded that the application of competitive learning can develop the character of fourth grade students SDN 3 sukaluyu Bandung in learning volleyball.
\end{abstract}




\section{PENDAHULUAN}

Pendidikan jasmani diartikan sebagai pendidikan melalui dan dari aktivitas jasmani. Siedentop (1991), dalam Rohmah \& Carsiwan (2013: hlm 98) mengatakan sebagai "education through and of physical activities" permainan, rekreasi, ketangkasan, olahraga, kompetisi, dan aktivitas-aktivitas fisik lainnya.

Pendidikan jasmani memusatkan diri pada semua bentuk kegiatan aktivitas jasmani yang mengaktifkan otot-otot besar (gross motoric), memusatkan diri pada gerak fisikal dalam permainan, olahraga, dan fungsi dasar tubuh manusia. Pendidikan jasmani merupakan peranan penting bagi di sekolah dasar karena untuk memberikan kesempatan peserta didik terlibat dalam berbagai pengalaman belajar. yang diarahkan untuk menumbuhkan pertumbuhan fisik ke arah yang lebih baik dan untuk membentuk gaya hidup yang aktif dan sehat. Tujuan yang ingin dicapai dalam aktivitas jasmani yaitu mencakup, aspek fisik, intelektual, emosional dan moral.

Pada hakikatnya pendidikan jasmani merupakan proses pendidikan yang memanfaatkan aktivitas fisik untuk menghasilkan perubahan dalam kualitas individu, baik fisik, mental maupun emosional. Hal ini dapat terjadi karena idealnya pendidikan jasmani memperlakukan anak sebai sebuah sesatuan yang utuh, makhluk total, dari pada hanya menganggapnya sebai seseorang yang terpisah kualitas fisik dan mentalnya.

Ada beberapa karakteristik anak di usia sekolah dasar yang perlu diketahui oleh guru agar lebih mengetahui keadaan peserta didik khususnya di sekolah dasar. Sebagai guru harus dapat menerapkan metode pengajaran yang sesuai dengan keadaan siswa maka, sangatlah penting bagi seorang pendidik untuk mengetahui karakteristik siswanya.. Pembelajaran penjas di sekolah dasar sangatlah penting, telah diketahui bersama bahwa anak-anak memiliki kecenderungan untuk bergerak terutama dalam berolahraga (Junaidi, 2016). Mereka senang untuk melakukan gerak karena, bagi mereka bergerak adalah suatu tujuan yang ingin dicapai dalam kehidupannya.

Pembelajaran bolavoli di SD Negeri 3 Sukaluyu selama ini masih kurang dilaksanakan karena siswanya masih mengalami kesulitan dalam memahami penguasaan gerak dalam permainan bolavoli. Sementara penguasaan yang diperlukan dalam permainan bolavoli secara efektif adalah bergerak kearah bola, pasing, mengumpan bola, servis, spike, blok dan penyelamatan bola (Suherman, 2016). Penguasaan keterampilan gerak bermain bolavoli akan menentukan hasil yang akan diperoleh setiap regunya. Dengan menguasai keterampilan tersebut yakni akan membantu dan menerima serangan dari lawan.

Menurut Subroto \& Yudiana (2013, hlm 23), penguasaan keterampilan bermain bola voli bagi anak-anak sekolah khususnya Sekolah Dasar, bukan merupakan satu-satunya tujuan yang hendak dicapai dalam proses pembelajaran, namun ada tujuan pendidikan lain yang harus ditumbuhkan dalam diri siswa sebagai individu yang sedang tumbuh dan berkembang. Tujuan tersebut adalah pengembangan seluruh potensi yang dimiliki siswa baik yang melibatkan aspek kognitif, afektif, dan psikomotor. Hal lain yang harus diperhatikan oleh seorang guru penjas dalam proses pembelajaran adalah perbedaan kemampuan setiap individu. Karena, setiap 
siswa akan memiliki perbedaan dalam hal kemampuan, baik kemampuan fisik, bentuk dan ukuran tubuh, minat, bakat, motivasi dan sebagainya. Oleh karena itu guru dituntut untuk selalu berkreasi dalam meningkatkan pembelajaran. Pelaksanaan pembelajaran pendidikan jasmani di sekolah guru memilih pendekatan pembelajaran yang tepat, yaitu menggunakan pendekatan kompetitif dimana peserta didik dilibatkan untuk berkompetisi dengan temantemannya untuk memenangkan suatu pertandingan dalam permainan bolavoli. Sehingga akan mendukung keberhasilan siswa terhadap proses pembelajaran dan dapat meningkatkan karakter siswa.

Menurut Kamimura, (2010. hlm 708) Pembelajaran kompetitif digunakan sebagai dasar metode baru kami. Pembelajaran kompetitif telah dilakukan salah satu metode pembelajaran yang paling penting dimana hanya seorang pemenang yang harus diupdate. Pembelajaran kompetitif sangatlah penting untuk diberikan kepada siswa. Dalam situasi belajar siswa akan mandiri dan bekerja keras untuk mencapai kesuksesannya. Sehingga kesuksesan dan kegagalan seseorang tidak akan berpengaruh terhadap kelompoknya. Dalam situasi belajar dilapangan, skor yang paling tinggi di peroleh seseorang akan mempengaruhi skor terhadap kelompoknya, sehingga seorang individu akan bertanggungjawab terhadap keberhasilan dan kegagalan dalam kelompoknya. Tidak jarang juga guru menggunakan pembelajaran kompetitif karena untuk memotivasi siswa untuk mencapai kemenangan dalam suatu pertandingan antar pelajar.

\section{METODE PENELITIAN}

Metode penelitian ini menggunakan penelitian tindakan kelas Penelitian ini merupakan suatu penelitian yang berbentuk kajian yang bersifat reflektif oleh pelaku tindakan yang dilakukan untuk meningkatkan kemantapan siswa dalam proses pembelajaran.

Penelitian dilakukan selama empat minggu (empat kali pertemuan atau tindakan). Subjek penelitian adalah siswa kelas IV berjumlah 35 orang, terdiri atas 25 orang siswa laki -laki dan 10 putri. Data dianalisis menggunakan teknik persentase. Instrumen yang digunakan dalam penelitian ini adalah lembar observasi

\begin{tabular}{|l|l|}
\hline PERILAKU YANG DIHARAPKAN & CEK $(\sqrt{ })$ \\
\hline A. Tanggung Jawab & \\
\hline 1. Menjaga keselamatan diri sendiri & \\
\hline $\begin{array}{l}\text { 2. Menggunakan peralatan } \\
\text { pembelajaran sesuai dengan } \\
\text { penggunaannya. }\end{array}$ & \\
\hline B. Sportif & \\
\hline 1. Menghargai teman satu tim dan & \\
\hline 2. Mentaati peraturan permainan & \\
\hline C. Kerja Sama & \\
\hline 1. Bekerja sama dengan Tim & \\
\hline 2. Bekerja sama dengan Diri Sendiri & \\
\hline Jumlah & \\
\hline Jumlah Skor Maksimal 24 & \\
\hline
\end{tabular}

Tabel 1.

Lembar Observasi Karakter

Keterangan: 
Skor 1, anak belum menunjukan perilaku yang diharapkan

Skor 2, anak mulai menunjukan perilaku yang diharapkan

Skor 3, anak menunjukan perilaku yang diharapkan tetapi terkadang masih diingatkan temannya

Skor 4, sudah menjadi kebiasaan anak secara otomatis dan tidak perlu diingatkan

\section{HASIL DAN PEMBAHAHASAN}

Berdasarkan tabel diatas rata keseluruhan karakter siswa dalam pembelajaran bola voli sebesar 37,63\%. Pada siklus I tindakan I diperoleh presentase siswa yang mendapatkan klasifikasi karakter yang belum muncul pada saat pembelajaran bola voli $6(17,14 \%)$, karakter siswa yang sudah mulai muncul dalam pembelajaran 15 (42,85\%), sedangkan karakter siswa yang muncul 12 (34,28\%), dan yang konsisten $2(5,71 \%)$. Sedangkan dalam Tindakan Siklus I tindakan II mendapatkan hasil dengan rata-rata keseluruhan karakter siswa dalam pembelajaran bola voli sebesar 43,92\%. Pada siklus I tindakan II diperoleh presentase siswa yang mendapatkan klasifikasi karakter yang belum muncul pada saat pembelajaran bola voli 9 (25,71\%), karakter siswa yang sudah mulai muncul dalam pembelajaran $8(22,85 \%)$, sedangkan karakter siswa yang muncul 12 (34,28\%), dan yang konsisten $9(25,71 \%)$.

Berdasarkan rata keseluruhan karakter siswa dalam pembelajaran bola voli sebesar 53,06\%. Pada siklus II tindakan I diperoleh presentase siswa yang mendapatkan klasifikasi karakter yang belum muncul pada saat pembelajaran bola voli $0(0 \%)$, karakter siswa yang mulai muncul dalam pembelajaran $0(0 \%)$, se- dangkan karakter siswa yang muncul 6 $(17,14 \%)$, dan yang konsisten 29 (82,85\%).

Berdasarkan rata keseluruhan karakter siswa dalam pembelajaran bola voli sebesar 63,43\%. Pada siklus II tindakan II diperoleh presentase siswa yang mendapatkan klasifikasi karakter yang belum muncul pada saat pembelajaran bola voli $0(0 \%)$, karakter siswa yang mulai muncul dalam pembelajaran $(0 \%)$, se-

\begin{tabular}{|c|c|c|c|c|c|}
\hline \multirow[b]{2}{*}{$\begin{array}{c}\text { Klasifi- } \\
\text { kasi }\end{array}$} & \multirow{2}{*}{$\begin{array}{c}\text { Ob- } \\
\text { serva } \\
\text { si } \\
\text { Awal }\end{array}$} & \multicolumn{2}{|c|}{ Siklus I } & \multicolumn{2}{|c|}{ Siklus II } \\
\hline & & $\begin{array}{c}\text { Tin- } \\
\text { dakan } \\
\text { I }\end{array}$ & $\begin{array}{c}\text { Tin- } \\
\text { dakan } \\
\text { II }\end{array}$ & $\begin{array}{c}\text { Tin- } \\
\text { dakan } \\
\text { I }\end{array}$ & $\begin{array}{l}\text { Tinda- } \\
\text { kan II }\end{array}$ \\
\hline $\begin{array}{c}\text { Konsis- } \\
\text { ten }\end{array}$ & $\begin{array}{l}0 \\
(0 \%)\end{array}$ & $\begin{array}{c}1 \\
(2,85 \\
\%)\end{array}$ & $\begin{array}{c}10 \\
(28,5 \\
7 \%)\end{array}$ & $\begin{array}{c}30 \\
(85,7 \\
1 \%)\end{array}$ & $\begin{array}{c}32(91, \\
42 \%)\end{array}$ \\
\hline Muncul & $\begin{array}{l}1 \\
(2,85 \\
\%)\end{array}$ & $\begin{array}{c}12 \\
(34,2 \\
8 \%)\end{array}$ & $\begin{array}{c}16 \\
(45,7 \\
1 \%)\end{array}$ & $\begin{array}{c}5 \\
(14,2 \\
8 \%)\end{array}$ & $\begin{array}{c}3 \\
(8,57 \%)\end{array}$ \\
\hline $\begin{array}{l}\text { Mulai } \\
\text { Muncul }\end{array}$ & $\begin{array}{l}11 \\
(31,4 \\
2 \%)\end{array}$ & $\begin{array}{c}15 \\
(42,8 \\
5 \%)\end{array}$ & $\begin{array}{c}9 \\
(25,7 \\
1 \%)\end{array}$ & $\begin{array}{c}0 \\
(0 \%)\end{array}$ & $0(0 \%)$ \\
\hline $\begin{array}{l}\text { Belum } \\
\text { Muncul }\end{array}$ & $\begin{array}{l}23 \\
(63,7 \\
1 \%) \\
\end{array}$ & $\begin{array}{c}6 \\
(17,1 \\
4 \%) \\
\end{array}$ & $\begin{array}{c}0 \\
(0 \%)\end{array}$ & $\begin{array}{c}0 \\
(0 \%)\end{array}$ & $0(0 \%)$ \\
\hline
\end{tabular}

dangkan karakter siswa yang muncul 3 $(8,57 \%)$, dan yang konsisten $32(91,42 \%)$.

Tabel 2. Perolehan Persentase Klasifikasi Karakter Siswa dari observasi Awal Siklus I dan Siklus II

Setelah penulis bertindak sebagai peneliti dan guru terjun langsung kelapangan serta dibantu oleh observer dalam melakukan PTK dari awal sampai akhir diperoleh dengan beberapa temuan yaitu:

\section{Dari hasil awal observasi diperoleh:}

Kurangnya kemampuan guru penjas dalam menerapkan pembelajaran kompetitif dalam upaya meningkatkan karakter siswa dalam pembelajaran bola voli. Guru penjas masih menggunakan teknik dalam penididikan jasmani sehingga siswa kurang antusias terhadap 
proses pembelajaran. Kurangnya variasi pembelajaran dan sarana prasarana pembeajaran kurang memadai.

\section{Dari hasil penelitian tindakan kelas}

Penyajian materi dan tugas gerak yang diberikan kepada siswa harus sesuai dengan tingkat kemampuan siswa dan karakterisitik siswa. seperti yang dikemukakan Juliantine (2012 hlm. 4). Bahwa dalam memilih materi ada tiga faktor yang harus diperhatikan yaitu sebagai berikut:

Urutan materi, yaitu harus terinstruktur secara sistematis, terurut dari yang termudah ke yang sukar, dari yang sederhana ke yang kompleks. Kelulusan materi, yaitu materi yang disesuaikan dengan ksiapan siswa, artinya jangan sampai materi jauh diatas kemampuan siswanya. Penggabungan materi, yaitu adanya keterkaitan antara satu sub pokok bahasan yang satu dengan yang lainnya. Pemberian materi dan penyajian tantangan melaksanakan tugas gerak sebaiknya berupa permainan agar siswa tertarik dan senang untuk melakukan proses pembelajaran.

Menurut Prasetyo, (2016 hlm 197) mengemukakan bahwa: Penedekatan bermain salah satu cara belajar yang dalam pelaksanaanya dilakukan dengan bentuk permainan. dalam penedekatan bermain siswa diberikan kebebasan untuk mengekspresikan kemampuannya terhadap tujuan pembelajaran yang telah ditetapkan. Dengan cara bermain siswa dapat memiliki kreativitas dan inisiatif untuk memecahkan sebuah masalah yang muncul selama proses pembelajaran berlangsung. Melalui bermain dikembangkan juga unsur kompetitif sehingga siswa saling menunjukan kemampuannya.
Berdasarkan uraian diatas pendekatan bermain merupakan cara belajar yang dilakukan dalam aktivitas bermain. Dengan aktivitas bermain siswa diberikan kebebasan untuk mengekspresikan kemampuannya. Dengan cara bermain siswa dapat memiliki kreativitas dalam pembelajaran.

Dalam pendidikan jasmani yang dilakukan dengan sungguh-sungguh dapat memberikan siswa siswa fokus terhadap proses pembelajaran sehingga mencapai target yang telah ditentukan. Pendidikan jasmani merupkan bagian integral dari pendidikan secara keseluruhan bertujuan untuk mengembangkan aspek kebugaran jasmani, keterampilan gerak, keterampilan berpikir, sosial, penelaran, emosional, moral, dan pola hidup sehat dan pengenalan lingkungan bersih melalui aktivitas penjas. Depdiknas ( dalam Widhyasari, 2017).

Menurut Kamimuara (2010, hlm 708) pembelajaran kompetitif digunakan sebagai dasar metode kami. Pembelajaran kompetitif telah dilakukan salah satu metode pembelajaran yang paling penting dimana hanya seorang pemenang harus diupdate. Dalam pembelajaran di kelas, David Johnson \& Johnson (1994), kompetitif yaitu dicirikan dengan adanya tujuan tapi tidak ada ketergantungan, suatu yang kompetitif dicirikan dengan adanya sikap negatif dalam hal ketergantungan, dimana seseorang menang maka yang lain kalah.

Pemebelajaran kompetitif adalah dicirikan dengan adanya sikap negatif dalam hal ketergantungan dimana ketika seseorang menang berarti yang lain kalah. Dalam situasi belajar siswa akan mandiri dan bekerja sendiri dalam mencapai kesuksesan, sehingga kesuksessan dan kegagalan sesorang tidak akan 
berpengaruh terhadap kelompoknya. (Aziz, R dalam Jurnal)

Pembelajaran kompetitif dicirikan dengan adanya sikap negatif dan ketergantung. Dimana seseorang menang maka yang lain berarti kalah. Dengan menggunakan model pembelajaran kompetitif siswa memiliki kebebasan untuk berperan dalam kehidupannya dan dapat menentukan hasil prestasi belajar dengan sendirinya dan siswa tidak lagi ketergantungan oleh guru.

\section{KESIMPULAN}

Penerapan pembelajaran kompetitid dapar meningkatkan perkembangan karakter siswa dalam pembelajaran bola voli.

\section{DAFTAR PUSTAKA}

Aziz, R,. (2008). Penggunaan Model Pembelajaran Kooperatif dan Kompetitif. Madrasah, $1 \quad$ (1). http://repository.uinmalang.ac.id/367/1/Kooperatif\%20dan\% 20Kompetitif.pdf. Diakses 1 juli 2008

Budiman \& Hidayat, (2011). Psikologi Anak dalam Pendidikan Jasmani. Bandung: RedPoint

Johnson, D, W, Johnson, R. (1975-1999). Learning Together and Alone: Cooperative, Competitive and Individualistic Learning. Baston: Allyn \& Bacon. First Edition 1975.

Juliantine, T dkk. 2012. Belajar dan Pembelajaran Penjas. Fakultas Pendidikan Olahraga dan Kesehatan. Universitas Pendidikan Indonesia

Junaidi, J. (2016). Pengaruh Gaya Mengajar Resiprokal Dalam Pembelajaran Permainan Bola Voli Terhadap Pengembangan Kreativitas Siswa. JURNAL PENDIDIKAN JASMANI DAN OLAHRAGA, 1(1), 17-26.

Kamimura, (2010). Information enhancement for interpreting competitive learning. Inter- natoinal Journal of General System, 38 (7) 705-728. Diakses 2 Desember 2014

Mahendra, Agus. 2015. Filssafat Pendidikan Jasmani. Fakultas Pendidikan Olahraga dan Kesehatan. Universitas Pendidikan Indonesia: CV. Bintang WarliArika

Marhaendro D, S, A,. (2010). Model Pendidikan Jasmani Berbasis Kompetisi. Journal. (Online). http://journal.uny.ac.id/index.php/ jpji/article/view/483. Diakses 2010

Prasetyo, koko. 2016. Penerapan Pembelajaran Bermain Untuk Meningkatkan Hasil Belajar Gaya Jongkok Pada Siswa Kelas 5 Sekolah Dasar. Schoralia.6.(3). 196-205

Rohmah \& Carsiwan., (2013). Sport History and Philosophy. Bandung: RedPoint

Subroto, \& Yudiana., (2013). Permainan Bola Voli. Bandung: Redpoint.

Subroto, T \& Yudiana, Y,. (2013). Permainan Bola Voli. Fakultas Pendidikan Olahraga dan Kesehatan. Universitas Pendidikan Indonesia. Bandung: Redpoint

Subroto, T dkk. 2016. Buku Pedoman Penulisan Penelitian Tindakan Kelas dalam Pendidikan Jasmani, Olahraga, dan Kesehatan. Universitas Pendidikan Indonesia. Bandung

Suherman, A. (2016). PENGARUH PENERAPAN MODEL KOOPERATIF TIPE JIGSAW DAN TGT (TEAMS GAME TOURNAMENT) TERHADAP KETERAMPILAN SOSIAL DAN KETERAMPILAN BERMAIN BOLAVOLI. JURNAL PENDIDIKAN JASMANI DAN OLAHRAGA, 1(2), 8 -15 .

Widyhasari,N dkk. 2017. Implementasi model pembelajaran kooperatif tipe numerd head together (Nht) Untuk meningkatkan aktivitas dan hasil belajar teknik dasar pasing. Jurnal pendidikan jasmani kesehatan dan rekreasi. 7. (1) tersedia :http//ejournal.undiksha.ac.id/ index.php/JJP/articel/view/9452/6040 